\title{
Mauricio Pelayo González. Los que no volvieron. Los muertos en la Guerra del Pacífico. Santiago. Ril Editores, 2019, 346 págs.
}

La muerte en la Guerra del Pacífico es un tema que no ha sido comúnmente abordado en las investigaciones historiográficas, razón por la cual, el libro de Mauricio Pelayo, titulado Los que no volvieron. Los muertos en la Guerra del Pacífico, resulta ser un trabajo novedoso, que se centra tanto en el análisis de muertes de los soldados en el campo de batalla como también en los asesinatos, suicidios, accidentes, defunciones presuntas, entre otras trágicas causas que nos acercan a reflexionar en torno la historia de la muerte.

El sentido de la publicación obedece a dos factores, el primero, debido a que que pronto se cumplirán 140 años del inicio de la Guerra del Pacífico, un conflicto sangriento entre los vecinos Chile, Perú y Bolivia, en el cual las tropas combatieron ferozmente sacrificando sus vidas por el amor a su patria. El segundo factor permite discernir el propósito del libro: Mauricio Pelayo decide rescatar del olvido a los caídos en la epopeya, los guerreros que se encontraban en el anonimato que se lanzaron a la guerra dejando a sus familiares por servir en el ejército chileno.

En este libro, Pelayo González introduce a diversas temáticas de interés en torno a los muertos en la Guerra del Pacífico. Esta es la historia de los soldados que murieron en los variados escenarios bélicos de la epopeya del '79. Es también un estudio sobre aquellos hombres valerosos que no tuvieron miedo a combatir contra sus rivales, que transitaron por lugares que se debían conquistar y donde encontrarían grandes peligros. Por último, es un libro para los amantes de la Guerra del Pacífico que siempre están sedientos de curiosidad intelectual, dispuestos a aprender nuevos antecedentes históricos que permiten conocer más sobre el conflicto del año 1879.

El texto de Pelayo esinteresante por los antecedentes que presenta: la lista de los soldados muertos, las fotografías de la época y otras fuentes rescatadas de investigaciones de autores contemporáneos que trabajan la Guerra del Pacífico. El estudio es un aporte interesante porque, además, su relato lo hace más ameno, muestra que hay un dialogo con los documentos. Sin embargo la recopilación de fuentes también presenta una debilidad, porque en la introducción del texto, Mauricio Pelayo expone que ha revisado y recopilado diversas fuentes provenientes del Archivo Nacional de Chile, Archivo del Ejército y el Naval; esta promesa entusiasma, aunque al leer los capítulos se desploma y es incomprensible por qué el autor sostiene que ha investigado diversos archivos

\footnotetext{
Jorge Orellana Billiard.

Mauricio Pelayo González. Los que no volvieron. Los muertos en la Guerra del Pacífico. Autoctonía. Revista de Ciencias Sociales e Historia, Vol. IV, N 1 , Enero-Junio 2020, 139-141 ISSN 0719-8213

DOI: http://dx.doi.org/10.23854/autoc.v4i1.156
} 
cuando solo hay uno citado. Revisando las notas a pie de página, es posible ver que Pelayo se refiere a periódicos que fueron citados de otros autores; por ejemplo hace referencia a una noticia del periódico El Mercurio sobre la batalla de Pisagua (1879), al principio se cree que el autor revisó este material pero en la cita aparece el texto de Benjamín Vicuña Mackenna (1883), Álbum de la Gloria de Chile (...). Lo mismo ocurre cuando se avanza en el libro y se descubre que los Fondos que el autor revisó en el Archivo Nacional tuvieron un resultado negativo, tampoco se encuentran los Fondos investigados en el Archivo del Ejército, a excepción de documentos del Departamento de Historia Militar, Archivo Correspondencia, que se citaron para explicar sobre el inventario del armamento y las prendas del Ejército.

Con todo, y contrariamente a lo que se podría pensar, el libro se lee sin dificultad. El autor escribe con legibilidad, elocuencia y una pluma grata, las circunstancias de la guerra, los problemas que vivieron los soldados en el campo de batalla y en los campamentos, hay un lenguaje ameno que permite que el lector comprenda las ideas que expone.

El libro de Mauricio Pelayo se compone de varios pasajes, pero no está dividido en capítulos. Está organizado, por el contrario, a partir de los títulos de las campañas que va a analizar. En primer lugar, "El Combate de Calama" está dedicado a analizar la muerte de los soldados del regimiento Cazadores a Caballo. Es un estudio breve, en el que toma este caso recurriendo a una cita del libro de Benjamín Vicuña Mackenna (1880) La campaña de Tarapacá (...), desde donde inserta la nómina de los caídos en combate; no obstante Pelayo vuelve a cometer un error en su investigación, porque no se encuentra su reflexión propia sobre el conflicto en Calama, la muerte de los soldados, los factores que ocasionaron la defunción de estos hombres. El autor podría haber recurrido a Partidas de Defunción de la Guerra del Pacífico y eso contribuiría a su reflexión sobre los casos expuestos, sin tener que recurrir a historiadores contemporáneos y los datos que estos presentaron.

Luego, "Asalto y toma de Pisagua" es un capítulo que explora la muerte de los Guardiamarinas y aspirantes de Marina, la muerte del guardiamarina Luis Victoriano Contreras, la del aspirante Miguel Ángel Isaza Flores, quien siendo estudiante del Colegio de los Sagrados Corazones de Santiago murió en aquel combate y cuyos restos se perdieron, aunque el propio Pelayo recorrió las lapidas de los distintos cementerios y encontró su tumba, teniendo la oportunidad de honrar su memoria como el autor comenta en su libro. En "El combate de Agua Santa", una de las batallas posteriores de la Guerra del Pacífico, se devela la identidad de los soldados caídos en el combate, cómo murieron, por qué razón y dónde se encuentran enterrados. Un aspecto positivo de estudio es que exhibe las fotografías de los esqueletos de estos militares encontrados recientemente, algo interesante para los amantes de la Guerra del Pacífico; el propio Pelayo comenta que exhibir las fotografías permite que los chilenos asistan a ese lugar a honrar la memoria de los combatientes.

A modo de conclusión, el libro Mauricio Pelayo González sobresale por su rigurosidad en el trabajo, un buen manejo de fuentes, aunque considero 
que podría mejorar mucho más acercándose a la revisión de los archivos que inicialmente comentó que revisó. En líneas generales, Pelayo trabajó un tema que nos hace reflexionar sobre la muerte de nuestros combatientes en la Guerra del Pacífico, soldados que se lanzaron a defender la patria amenazada, encontraron la muerte en el campo de batalla y que pasan desapercibidos por las actuales generaciones. El libro de Mauricio Pelayo nos permite revivir nuevos temas historiográficos sobre la Guerra del Pacífico y nos acerca mucho más al pasado de nuestros héroes.

\section{Referencias citadas:}

Vicuña Mackenna, B. (1880): Historia de la Campaña de Tarapacá. Desde la ocupación de Antofagasta hasta la proclamación de la dictadura en el Perú, Santiago de Chile, Rafael Jover.

Vicuña Mackenna, B. (1883): Álbum de la gloria de Chile: homenaje al Ejército i Armada de Chile en la memoria de sus más ilustres marinos i soldados muertos por la patria en la Guerra del Pacífico: 1879-1883, Santiago de Chile, Impr. Cervantes.

Jorge Orellana Billiard. Programa de Doctorado en Historia. Pontificia Universidad Católica de Valparaíso. 